\title{
What Do Family Physicians Believe and Value in Their Work?
}

\author{
George William Saba, PbD
}

Background: Family practice has always valued physician self-awareness. Whereas self-awareness has traditionally focused on problem relationships with patients, generally unexplored are the physicians' personal beliefs and values that strongly influence their routine clinical work and collegial relationships. Thus we know little about the nature and scope of these beliefs and values. The following study was undertaken to foster a better understanding of beliefs and values that residents bring to their clinical practice.

Metbods: Applying 13 years of experience with one method of structured reflection and conversation, I was able to perform a cross-set analysis of findings from interactions with 143 family practice residents. Such dimensions as views of life and death, role of physician, and process of healing served as avenues to elicit beliefs and values.

Results: The residents' responses yielded the following six themes: philosophy and spirituality, the nature of suffering, the strains of helping, the healing relationship, the coherence of models, and clashes with the models of patients and colleagues.

Conclusion: These conversations with family physicians-in-training suggest that they bring to their clinical and collaborative relationships complex, highly personal models of medicine that emphasize meaning and human relationship and serve as a source of strength. To better understand these models, future work should investigate the general beliefs and values of experienced family physicians in various practice settings, how their models of medicine interact and perhaps clash with those of their patients and colleagues, and effective methods for helping family physicians articulate their views so they can function effectively in their clinical practice. (J Am Board Fam Pract 1999;12:206-13.)

As health care reform pushes into the 21 st century, the importance of the person of the physician is being rediscovered. The recent emphasis on relationship-centered care has highlighted that who physicians are profoundly influences the quality of care they give and the quality of relationships they can form. A relationship-centered approach requires that physicians have skills in self-awareness and a capacity for reflection to be able to work effectively with patients and colleagues. ${ }^{1-5}$

If self-awareness and reflection are so fundamental to physicians functioning effectively, what should their focus be? The traditional emphasis has been on physicians' personal issues triggered by problems in the physician-patient relationship (eg, Balint training). ${ }^{6}$ A growing body of literature suggests that another impor-

Submitted, revised, 9 September 1998.

From the Department of Family and Community Medicine, University of California, San Francisco. Address reprint requests to George William Saba, $\mathrm{PhD}$, Family Practice Residency Program, Room 333, Ward 83, Building 80, San Francisco General Hospital, 1001 Potrero Ave, San Francisco, CA 94110. tant focus should be the beliefs and values that physicians bring to routine clinical care and collaborative relationships. ${ }^{7-27}$

As early as 1970 , Carmichael ${ }^{7}$ described family practice as a unique medical specialty in part because it valued physician self-awareness. $\mathrm{He} \mathrm{ob-}$ served that family physicians develop a system of attitudes, beliefs, and values that unconsciously determine much of their thinking and behavior in clinical practice and that the medical profession is obliged to understand these systems.

The literature, however, sheds little light on the nature of these systems. Research generally explores physicians' views about specific disease management (eg, diabetes) ${ }^{12-20}$ or ethical issues (eg, abortion, end-of-life care, patient autonomy). ${ }^{21-27}$ More is known about what beliefs and values patients bring to the examination room. Their belief systems are complex, vary considerably, and are influenced by their families, community, and cultures. ${ }^{28-31}$ An understanding of the broader systems of attitudes, beliefs, and values of family physicians, however, lags behind. As Carmichael suggests, family physicians are obliged to 
understand the domain of beliefs and values that operate in clinical care.

Given the current interest in physician selfawareness and the dearth of literature about what family physicians bring to their clinical and collaborative relationships, I conducted a retrospective review of structured explorations of the beliefs and values of 143 family practice residents. The purpose of this article is to present the analysis of that review so that it can serve as a starting point for the further study of the nature and scope of family physicians' beliefs and values.

\section{Methods}

As the behavioral science faculty member of a family practice residency program, I have had the opportunity to explore what young physicians find meaningful in their work. In $1985 \mathrm{I}$ wanted to incorporate into the curriculum a more formal process to help residents articulate personal beliefs and values related to clinical medicine. A literature search yielded few methods for accessing the interior life of physicians. In the family therapy field, Liddle $^{32}$ called for clinicians to articulate their personal models of psychotherapy. After adapting his framework to a medical context, I conducted preliminary inquiries with 12 family practice residents in focus groups. The discussions generated a list of dimensions with related questions (Table 1), and an exercise was developed that allowed residents to reflect on these dimensions and share them with each other. In 1986 this exercise was integrated into the behavioral science curriculum for 3 rd-year residents to help them focus their own views about medicine.

\section{Exercise}

As part of the 3rd-year behavioral science curriculum, ${ }^{3-5}$ residents work as a group to acquire advanced therapy skills in family systems care and focus on professional development. They meet weekly in 4-hour sessions for 3 months. Early in this curriculum, during one of the 4-hour sessions, the faculty (the author and generally a family physician) tell the residents that they will participate in an exercise to facilitate awareness of their beliefs and values by individual reflection and collegial dialogue. Because these residents will, as a group, also learn skills in family systems care, they are told that another purpose of this exercise is to provide a database about their per-
Table 1. Physician's Beliefs and Values About Clinical Care: Some Dimensions for Consideration.

\begin{tabular}{ll}
\hline Dimension & Questions That Elicit Beliefs and Values \\
\hline Life and death & $\begin{array}{l}\text { What do I believe about the meaning of } \\
\text { our life? Do I believe life has a purpose? } \\
\text { Is there any life after death? }\end{array}$ \\
Health and illness & $\begin{array}{l}\text { How do I define health and illness? How } \\
\text { does someone become sick? How does } \\
\text { someone stay healthy? }\end{array}$ \\
Role of the & $\begin{array}{l}\text { What do I see as my role(s)? Am I a } \\
\text { physician } \\
\text { teacher, adviser, problem-solver? }\end{array}$ \\
Role of patients & $\begin{array}{l}\text { What do I think should be the role of } \\
\text { patients in their health care? How } \\
\text { motivated do they need to be? }\end{array}$ \\
The process of & $\begin{array}{l}\text { How do I believe that healing occurs? } \\
\text { healing }\end{array}$ \\
$\begin{array}{l}\text { What is the involvement of the patient } \\
\text { in their healing process? What are the } \\
\text { necessary ingredients for people to } \\
\text { recover their health? }\end{array}$ \\
$\begin{array}{l}\text { How do I evaluate my efforts as a } \\
\text { physician? What points of outcome are } \\
\text { important in my assessment of my } \\
\text { evaluation } \\
\text { personal performance (eg, patient satis- } \\
\text { faction, reaching treatment goals, saving } \\
\text { lives, prevention)? }\end{array}$ \\
\hline
\end{tabular}

sonal views to compare later with their actual work with patients.

Next they are asked to reflect individually on routine and critical incidents in practice that have occurred not only during medical school and residency but also during personal or family experiences of health and illness. Approximately $30 \mathrm{~min}$ utes are allotted for individual reflection using the questions in Table 1 as a guide. During the next 3 hours, they meet together with faculty facilitators to discuss these reflections collectively.

Faculty members take extensive notes during the group discussions to provide a record of the reflections and dialogue for these comparisons. During the last 30 minutes of the session, the facilitators read their notes to each participant to clarify what the participant had said and to correct any errors in recording. For example, a faculty member might say to a resident: "I want to be sure I am clear about this; you said...." These written records serve as a reference during the remaining rotation to compare what the resident had said with actual behavior during supervised sessions with patients. During the first year of this curriculum, the exercise sessions were videotaped, hoping to increase accuracy in the written records. The videotaping added little, however, and was discontinued. 
Table 2. Characteristics of Physician Participants (n - 143).

\begin{tabular}{lcc}
\hline Characteristics & Number & Percent \\
\hline Sex & & \\
$\quad$ Female & 89 & 60 \\
Male & 54 & 40 \\
Ethnicity & & \\
$\quad$ European-American & 82 & 57 \\
Asian-American & 21 & 15 \\
Latin-American & 17 & 12 \\
African-American & 6 & 4 \\
Pacific Islander & 12 & 8 \\
Middle Eastern-American & 3 & 2 \\
$\quad$ Native American & 2 & 1 \\
Medical school & & \\
$\quad$ United States & 140 & 2 \\
International & 3 & \\
\hline
\end{tabular}

\section{Sample}

This exercise has been conducted in the family practice residency at San Francisco General Hospital, University of California, San Francisco, a county hospital program whose mission is to train physicians to care for a multicultural, multiethnic, economically underserved patient population. All 3 rd-year residents participate in this exercise as part of a designated curriculum. The residents are grouped together on the basis of their annual schedule; thus, the groups do not self-select.

Since 1986, 143 residents in 38 separate sessions have participated in the exercise. Table 2 provides information about the participants. Anonymous evaluations of this exercise are conducted at the end of the behavioral science rotation. On a Likert scale in which the experience was judged from "least" to "most useful," 86 percent rated the experience "most useful," and 12 percent gave it the second highest rating.

\section{Analysis}

A retrospective analysis was made of the written records and the few videotapes of the participants' statements about their beliefs and values. Using the grounded theory method, I analyzed the data in the four sequential stages recommended by Strauss and Corbin. ${ }^{33}$ First, I read through the written records and viewed the videotapes to form general impressions. Second, using open-coding techniques, I analyzed each participant's responses to the dimensions to distinguish and label the types of statements (eg, cause of illness, a desire to help). Third, I used axial coding procedures to reanalyze statements to link coded data across dimensions. For example, a participant might talk about the desire to help when responding to the dimension of role of patient, role of physician, and the process of healing. Fourth, I used selective coding procedures for a broader interpretive analysis suggesting themes for each participant that cut across the responses to each question (eg, theory of suffering, strains of helping) and examined these themes using a cross-set analysis to discover which were common to the group of 143 residents.

\section{Results}

Reported here are those themes from the cross-set analysis that have consistently emerged with time. They do not represent statements about any specific dimension from Table 1 but reflect statements across all six dimensions common to the entire set of residents. The six themes, displayed in Table 3, are described below and are illustrated by statements from the participants' written and videotape records of the exercise sessions.

\section{Importance of a Pbilosopbical or Spiritual Framework}

All residents stated strong beliefs and values that reflected their personal philosophical or spiritual frameworks. These frameworks were central to how they viewed human existence, health and illness, and their role as a physician. They described how these frameworks provided moral guidance in their daily clinical decision making and helped them give meaning to the complex, uncertain, and often painful events in their clinical work.

Many ( 85 percent) explained that their desire to become a physician was rooted in a sense of mission or calling:

Ifelt that my purpose in life, that God's plan for me, was to become a doctor and belp people.

Sixty-three percent described their beliefs and values as reflecting formal philosophic or religious traditions:

As a Buddbist, death is not a bad thing; it is something to prepare for. I try to belp patients accept it ratber than offer them life-extending technology that may affect their process of dying.

I grew up Catbolic and believe in an afterlife. Death isn't a big deal. I can't see spending more money to lengthen a patient's life. I get upset that some doctors keep people alive because they bave the means of doing so.

I am an ortbodox atheist. When you're dead, you're dead. Life doesn't bave any meaning. I am not afraid of 
belping people live longer or belping them die if they want to. It's their choice.

For some (47 percent) these frameworks evolved dramatically with time, often following important events in their personal or professional lives:

I have changed over time. I was raised fewish and didn't believe in an afterlife. Then my brother died, and I know bis spirit is somewhere. I'm more comfortable caring for sick patients and their families knowing that there's a spiritual realm that they'll enter someday.

This is in flux for me ever since that patient died who I found really hard to like. Surprisingly, I'm not Christian, but I bave found grounding in sometbing Mother Teresa said. She sees Cbrist in all his distressing disguises in the patients she cares for. This has belped me feel there is meaning in some of my patients' illnesses and to care for people I'd ratber not.

Residents differed on whether they believed one's time of death was predestined (45 percent) or resulted from random biologic events (54 percent), and these beliefs affected how much influence they thought they had in patients' overall health:

I believe a time and date of death are assigned at the time of one's birth. As a doctor, I can't shorten or lengtben one's lifetime; I can belp make it as bealtby as possible.

I don't think people have a time they are supposed to die. So, I try to keep people alive as long as possible and as long as their quality of life is good. I do feel a bit of a failure when one of my patients dies, like maybe I should bave done more.

Although these participants held strong opinions, the majority ( 80 percent) commented that their views should not compromise patient care:

I try not to put my beliefs on patients. I went to a Catholic medical school and found it oppressive for me and the patients. It is hard to strike the right balance.

I'm not sure what I believe. I believe in an afterlife but don't think you get rewarded. Because I'm confused, I don't want to foist my view on patients. But I value young over old if I have a chance to prolong life. Young people haven't had an opportunity to live. I also value people's minds over bodies. If they are demented, I will do less to prolong their life than if they are intact and their body needs external supports to continue. But what if I'm wrong about all this?

\section{Theories of Suffering}

All residents stated reasons for human suffering to explain why people become ill. Although most residents (64 percent) said the causes were multi-
Table 3. Themes of Beliefs and Values from the Cross-set Analysis (n - 143).

Philosophical- Frameworks that are central to how one spiritual views human existence, health and illness, frameworks and role as physician. They provide moral guidance in clinical decision-making and give meaning to complex, uncertain, and painful events in clinical practice. These frameworks can operate in the decision to become a physician, reflect formal philosophic or religious traditions, and evolve with time

Theory of Explanations for why someone becomes sick, suffering experiences pain, and suffers. These theories address how a person has responsibility for becoming sick and for becoming well

Strains of Helping people who are in pain and suffer helping can be emotionally costly, leading to feelings of helplessness and ineffectiveness. How responsible one feels for helping, at all costs, and resolving patients' pain contributes to the amount of strain one experiences

Healing in Healing, an important focus of the clinical the patient- encounter, involves helping patients find physician meaning in the face of disease and occurs in relationship a human relationship in which patients are empowered, informed, and ready. The relationship adds considerably to feeling satisfied with one's clinical efforts

Congruence A congruence of beliefs and values can reveal a cohesive framework or model of how physicians views their clinical work. Reflection on the degree of consistency among beliefs and values can facilitate further development in the model

Power, If one's beliefs and values differ widely from permission, those of patients, family members, and and colleagues, difficulties can develop. Impasses difference can emerge when there are inequalities in power and a perceived sense that differences cannot be openly discussed

factorial, they differed on the degree to which they thought patients were responsible for acquiring disease. Some ( 22 percent) stated that a person bears no responsibility for becoming ill:

All disease is random. It's not God's way of telling you anything. You just take the good with the bad.

You can't blame the victims. It's eitber germs or spirits, but it's not their fault.

Alternatively, 14 percent said that a patient was completely responsible for becoming sick:

At some level, a person chooses to get sick. People need to take responsibility for that and not feel like victims.

Some (44 percent) expressed frustration and anger, particularly if patients were not taking measures to improve:

I feel bad saying this, but I am much more empathetic to someone who got AIDS from a transfusion than someone who got it from sexual contact or intravenous drug use. 
I get angry at alcobolics. I know it's a bad attitude, but I don't have sympathy. Other illnesses, like some cancers, aren't brought on by lifestyle. But some people bring it on themselves.

\section{Strains of Helping}

Many residents (76 percent) reported that their desires to help patients often came at great cost. Feeling responsible for resolving patients' pain and suffering, they described often feeling helpless and ineffective:

I started off wanting to belp as much as possible. I've worked so bard with some patients, and got frustrated when it didn't belp. I started to get cynical and angry and didn't want to get close again.

Many participants ( 55 percent) reported that their families, patients, and teachers have helped shape expectations of how far their reach should extend to help patients:

I want to help. It's a role I played in my family. I'm not sure it's best for me to continue doing, since it may lead to burnout.

I'm a fixer; I assume people come to the doctor because they want something fuxed. And I bave the expectation to do so. People want you to decide, and I end up assuming a parental role with all patients.

Everybody tells you to shut off your emotions and not care too much about patients or you'll get torn up every time one dies. During my surgery clerkship, I was told there was no room for my tears in the OR. I was crying after we lost a patient, and the attending told me it wouldn't belp me or the family to be upset.

Most (84 percent) said medical training tried to protect them by endorsing objectivity and detachment from the patient. They found this distance ultimately impossible to achieve, however, if even desirable. Various participants ( 32 percent) suggested reframing the concept of detachment. Rather than detaching from the patient, some found it helpful to detach from the belief that they should help others at all costs:

I think it's my wanting to save everyone that gets me in trouble; paradoxically it keeps me from getting too close to them. As a Buddhist, I am trying not to be so attached to my desire to belp. When I can do that, I bave no problem working closely with my patients."

\section{Healing in the Patient-Physician Relationship}

All residents made statements that they focus on healing during the clinical encounter. Whereas curing disease is a goal, some ( 31 percent) said that such opportunities were more limited than they had been taught and than patients expected. Most (86 percent) stated that healing involved helping patients find meaning even in the face of disease. They reported:

No matter bow sick someone is, they can be bealthy if they bave a purpose in their life. As a bealer, it's my job to belp them find meaning, even if they're dying.

For most ( 93 percent), the basis of a healing relationship was a strong human connection:

There needs to be compassion; you bave to be in the relationship "with passion" for patients to know you care. You also bave to instill a sense of bope and optimism.

All people bave some good in them. I try to connect bumanly. If we can do that then bealing can occur.

To enhance healing, these residents stated that patients should be informed, empowered, and ready for change:

I'll demystify medicine for you and tell you what the options of treatment cboices are. It's up to you. You bave to make a cboice given the consequences.

The power is always unequal, but I try to be bonest, and that belps patients be more in control of getting better.

I expect a patient to do what I ask. I've tried my best, and I'm furious if they don't try their best.

Physicians can only guide people, but they won't be bealed unless they do it themselves.

People need to be somewhat uncomfortable with their current condition; if they do not want to change it won't happen.

These physicians said that when a "healing relationship" was absent, they were less satisfied with the clinical encounter and themselves:

When the relationship with the patient is damaged, I feel I'm a bad pbysician.

One of the worst things about the demand to see so many patients is that I miss what is most important in my work. I don't feel I can be a bealer; I don't bave time to get to know the patient and their life. I feel I'm chasing symptoms and dispensing medicines.

\section{Congruence of Beliefs and Values}

When residents reflected on their responses to the dimensions, many ( 74 percent) remarked on how congruent their beliefs and values were, revealing a coherent framework:

I don't believe in God or an afterlife. While bere, we need to do something to make it a better world. Life needs to be given meaning by those who live it (life and death). People are bealthy when they are living life to 
the fullest, in a way that they feel their life is meaningful. This can happen even when people bave serious disease (health and illness). My role is to belp them decide what they can do to live their life in a satisfying manner (role of physician). But they bave to give me an idea of what satisfying means to them. I'm not afraid to be their friend, since we're all living bere for the same purpose (role of patient). It is in our developing a shared agenda for their bealth that I can make clinical decisions (process of healing). I feel I'm doing my job if they're satisfied with their care, continue to bave meaning regardless of the presence of disease, and bave a sense of greater well-being (outcome and evaluation). I guess this all bolds together; you could say it's my own model of medicine.

Within these personal frameworks, residents acknowledged that inconsistencies sometimes existed, often resulting from changing beliefs or critical incidents in patient care:

I grew up in a Buddbist culture where one's deatb was planned from birth. I should go with the flow; the soul lives on. I shouldn't try to make patients change their mind about their bealth care. But it's bard when they don't want to take care of themselves. I bave a patient with retinopatby who refuses laser treatment. I believe I should support ber decision. But if she goes blind, ber life will be worse. Becoming a physician bas made being a Buddbist more difficult. There's no longer an easy answer for me.

\section{Power, Permission, and Difference}

Many residents ( 81 percent) discussed how some of their most difficult clinical experiences occurred when their views clashed with those of colleagues, patients, and family members. Differences about the sacredness of life, the expectations of roles, and what they considered the appropriate course of treatment often led to impasses that were compounded by a perceived lack of permission to talk openly. Instead, they said their struggles were often cloaked in debates about the latest scientific evidence, subtle implications about each others' insensitivity, or threats of what might occur if advice is not followed:

There is no place to talk about these issues; and when your senior resident or attending disagrees, you don't feel comfortable being this open. They bave decisionmaking powver and ultimately evaluate you.

We never discuss our personal differences on rounds; people try to prove they are right by picking certain studies to support their view..., or else they'll make you feel guilty, "If that was your father, you wouldn't be so fast to pull the plug."

It's really bard when I'm working with a family from another culture who has expectations completely different from mine about what my role is. Sometimes the family doesn't want me to discuss with the patient the diagnosis or treatment. I end up sometimes saying less than I should or would with another patient, and sometimes distancing myself from the patient and the family.

\section{Discussion}

What can these family physicians-in-training tell us about the nature and scope of beliefs and values that guide clinical work and collaborative relationships? They bring deeply held, personal beliefs and values, which for many are not loosely related opinions but reflect their own models of medicine that help orient their thinking and action during ethically difficult moments and routine clinical care. While Kleinman ${ }^{28,29}$ suggests that physicians hold the same biomedical model of medicine, these physicians do not share the same model; their personal beliefs and values vary substantially and address a number of dimensions generally not considered in the biomedical approach.

For example, these physicians highlight the importance of meaning in their professional lives and in the process of healing. Their beliefs and values often focus on the whys they experience in practice (eg, Why am I a physician? Why do people suffer? Why do I feel so helpless?) rather than the hows (eg, How does a disease worsen? How does healing occur?). Their answers to these larger questions help guide them through the uncertainty and complexity of their clinical work and give a meaningful focus for their patient care. Interestingly, the PewFetzer Task Force ${ }^{1}$ reports that patients believe physicians have a limited capacity to sense meaning, especially at the affective and spiritual levels. Such, however, is not the case with these residents, who emphasize that their beliefs and values about meaning, suffering, and spirituality are central to who they are and what they do as family physicians, even if they rarely feel comfortable discussing them with patients or colleagues.

Their beliefs and values define the crucial role of human relationships in one's professional development and clinical practice. Becoming a family physician entails more than the acquisition and competent execution of technical skills. These physicians appreciate that how they think and act 
has been forged in the context of interpersonal relationships with their family, patients, colleagues, and teachers. In addition, the important task of healing demands a strong, vibrant human relationship. Repeatedly they speak of the need to consider trust, power, control, role, responsibility, and compassion in one's care, all of which resonate with a growing literature on the patient-physician relationship. ${ }^{34-38}$

Finally, these physicians appreciate that who they are as physicians positively affects the way they practice medicine. Often only physician characteristics are discussed as potential biases that, when unexamined, endanger patient care. ${ }^{39,40} \mathrm{Al}$ though aware of how their views might compromise care, these young physicians describe how their personal frameworks enhance clinical practice; in fact, they see their beliefs and values as sources of personal strength.

These conversations only begin to suggest the depth, richness, and variability that characterize family physicians' beliefs and values. A more formal, prospective inquiry is required. This study has certain weaknesses that should be addressed in future investigations. For example, this study was based on a retrospective review in which the data were originally collected for another purpose, ie, a training exercise. Because the data were generated by resident self-report, the trustworthiness of the data needs to be explored, such as in comparison with actual clinical behavior or with impressions by faculty, colleagues, and patients.

The sample represents a narrow cohort of 3 rdyear family practice residents in an urban underserved training program. Future study should include more experienced family physicians in various practice settings to explore whether they hold personal models of medicine. Do they struggle with the same issues that loom so large for these residents as they embark into practice? How do physicians' personal beliefs and values interact with those of patients and colleagues, and what happens when they clash? What are effective methods for assisting family physicians in selfawareness, reflection, and articulation that can enhance respect, openness to the values of others, and communication with patients and colleagues?

As family practice faces the uncertainties of health care reform and the economic realities of managed care, they need to reclaim an important part of their heritage-being clear on who they are and what they believe and value in their work. As a resident said weeks following the exercise: "It may sound paradoxical, but I am listening to my patients better since I can hear my voice more clearly." The experience of the last 13 years suggests that systematic reflection of beliefs and val- $\frac{0}{0}$ ues promotes self-knowledge, which can foster creativity and guard against decisions that compromise care. The sharing of these views with trusted colleagues can facilitate mutual understanding and reduce the isolation often experienced in practice. At a time when the medical landscape is rapidly shifting, checking individual and collective bearings can help remind family physicians what is unique and meaningful about their work.

The family practice residents and faculty facilitators have participated in this work. Without their willingness to hon- $\omega$ estly discuss their deeply personal reflections of their clinical experiences, I would be unable to understand or communicate the power of the dialogue. Teresa Rebeiro, MD, Teresa Villela, MD, Peter Sommers, MD, Ronald Goldschmidt, MD, Kevin Grumbach, MD, and Laurie Kalter, MA, provided invaluable critical review.

\section{References}

1. Health professions education and relationship-centered care: report of the Pew-Fetzer Task Force on Advancing Psychosocial Health Education. San Francisco: Pew Health Professions Commission, 1994.

2. Glass RM. The patient-physician relationship. JAMA focuses on the center of medicine. JAMA 1996;275:147-8.

3. Laine C, Davidoff F. Patient-centered medicine. A professional evolution. JAMA 1996;275:152-6.

4. Donaldson MS, editor. Primary care: America's health in a new era. Committee on the Future of Primary Care, Division of Health Care Services, Institute of Medicine. Washington, DC: National Academy Press, 1996.

5. Novack DH, Suchman AL, Clark W, Epstein RM, Najberg E, Kaplan C. Calibrating the physician. Personal awareness and effective patient care. Working Group on Promoting Physician Personal Awareness, American Academy on Physician and Patient JAMA 1997;278:502-9.

6. Epstein RM, Campbell TL, Cohen-Cole SA, McWhinney IR, Smilkstein G. Perspectives on patientdoctor communication. J Fam Pract 1993;37: 377-88.

7. Carmichael LP. Psychiatry and family medicine: the behavioral disciplines. The New Physician 1970;19: 524-7.

8. Argyris C, Schon DA. Theory in practice: increasing professional effectiveness. San Francisco: Jossey-Bass, 1974.

9. Argyris C, Schon DA. Organizational learning

.

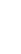

.

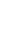


Reading, Mass: Addison-Wesley, 1978.

10. Schon DA. The reflective practitioner: how professionals think in action. New York: Basic Books, 1983.

11. Schon DA. Educating the reflective practitioner: toward a new design for teaching and learning in the professions. San Francisco: Jossey-Bass, 1990.

12. DiMatteo MR, Sherbourne CD, Hays RD, Ordway L, Kravitz RL, McGlynn EA, et al. Physicians' characteristics influence patients' adherence to medical treatment: results from the Medical Outcomes Study. Health Psychol 1993;12:93-102.

13. Anderson LA, Zimmerman MA. Patient and physician perceptions of their relationship and patient satisfaction: a study of chronic disease management. Patient Educ Couns 1993;20:27-36.

14. Anderson RM, Donnelly MB, Gressard CP, Dedrick RF. Development of diabetes attitude scale for health-care professionals. Diabetes Care 1989;12: 120-7.

15. Anderson RM, Fitzgerald JT, Gorenflo DW, Oh MS. A comparison of the diabetes-related attitudes of health care professionals and patients. Patient Educ Couns 1993;12:41-50.

16. Cohen $M Z$, Tripp-Reimer T, Smith C, Sorofman B, Lively S. Explanatory models of diabetes: patient practitioner variation. Soc Sci Med 1994;38:59-66.

17. Gillespie CR, Bradley C. Causal attributions of doctor and patients in a diabetes clinic. Br J Clin Psychol 1988;27(Pt 1):67-76.

18. Bennet IJ. Do doctors address the concerns of patients with diabetes? Diabet Med 1994;11:586-9.

19. Boult L, Boult C. Underuse of physician services by older Asian-Americans. J Am Geriatr Soc 1995;43: 408-11.

20. Kaplan SH, Greenfield S, Ware JE Jr. Assessing the effects of physician-patient interactions on the outcomes of chronic disease. Med Care 1989;27(3 Suppl):S110-27.

21. Casanueva E, Lisker R, Carnevale A, Alonso E. Artitudes of Mexican physicians toward induced abortion. Int J Gynaecol Obstet 1997;56:47-52.

22. Rutecki GW, Cugino A, Jarjoura D, Kilner JF, Whittier FC. Nephrologists' subjective attitudes towards end-of-life issues and the conduct of terminal care. Clin Nephrol 1997;48:173-80.

23. Asai A, Fukuhara S, Inoshita O, Miura Y, Tanabe N, Kurokawa K. Medical decisions concerning the end of life: a discussion with Japanese physicians. J Med
Ethics 1197;23:323-7.

24. Kopelman LM. Philosophy and medical education. Acad Med 1995;70:795-805.

25. Reiser DE, Rosen DH. Medicine as a human experience. Baltimore: University Park Press, 1984.

26. Emanuel EJ, Emanuel LL. Four models of the physician-patient relationship. JAMA 1992;267: 2221-6.

27. Quill TE, Brody H. Physician recommendations and patient autonomy: finding a balance between physician power and patient choice. Ann Intern Med 1996;125:763-9.

28. Kleinman A. Patients and healers in the context of culture: an exploration of the borderland between anthropology, medicine, and psychiatry. Berkeley, Calif: University of California Press, 1980.

29. Kleinman A. The illness narratives: suffering, healing, and the human condition. New York: Basic Books, 1988.

30. Blackhall LJ, Murphy ST, Frank G, Michel V, Azen S. Ethnicity and attitudes toward patient autonomy. JAMA 1995;274:820-5.

31. Carrese JA, Rhodes LA. Western bioethics on the Navajo reservation. Benefit or harm? JAMA 1995; 274:826-9.

32. Liddle HA. On the problems of eclecticism: a call for epistemologic clarification and human-scale theories. Fam Process 1982;21:243-50.

33. Strauss AL, Corbin JM. Basics of qualitative research: grounded theory, procedures and techniques. Newbury Park, Calif: Sage Publications, 1990.

34. Brody H. The healer's power. New Haven, Conn: Yale University Press, 1992.

35. Candib LM. Medicine and the family: a feminist perspective. New York: Basic Books, 1995.

36. Cassell EJ. The nature of suffering and the goals of medicine. New York: Oxford University Press, 1991.

37. Thom DH, Campbell B. Patient-physician trust: an exploratory study. J Fam Pract 1997;44:169-76.

38. Suchman AL, Markakis K, Beckman HB, Frankel R. A model of empathic communication in the medical interview. JAMA 1997;277:678-82.

39. Marshall AA, Smith RC. Physicians' emotional reactions to patients: recognizing and managing countertransference. Am J Gastroenterol 1995;90:4-8.

40. Gorlin R, Zucker HD. Physicians' reaction to patients. A key to teaching humanistic medicine. $\mathrm{N}$ Engl J Med 1983;308:1059-63. 